\title{
Prevalence of functional dependence in Chinese centenarians and its relationship with serum vitamin $D$ status
}

\section{Yao Yao ${ }^{1, *}$ \\ Shihui $\mathrm{Fu}^{2, *}$ \\ Qiuling Shi ${ }^{3}$ \\ Hao Zhang ${ }^{4}$ \\ Qiao Zhu ${ }^{5}$ \\ Fu Zhang ${ }^{5}$ \\ Fuxin Luan ${ }^{5}$ \\ Yali Zhao ${ }^{5}$ \\ Yao $\mathrm{He}^{1}$}

'Institute of Geriatrics, Beijing Key Laboratory of Aging and Geriatrics, National Clinical Research Center for Geriatric Diseases, Chinese PLA General Hospital, Beijing, People's Republic of China; ${ }^{2}$ Department of Geriatric Cardiology, Chinese PLA General Hospital, Beijing, People's Republic of China; ${ }^{3}$ Department of Symptom Research, MD Anderson Cancer Center, Houston, TX, USA; ${ }^{4}$ Department of Health Policy and Management, Texas A\&M University, College Station, TX, USA; ${ }^{5}$ Central Laboratory, Hainan Branch of Chinese PLA General Hospital, Sanya, People's Republic of China

*These authors contributed equally to this work

Correspondence: Yao He Institute of Geriatrics, Chinese PLA General Hospital, Fuxing Road 28, Beijing 100853, People's Republic of China Email yhe30I@x263.net

Yali Zhao

Central Laboratory, Hainan Branch of Chinese PLA General Hospital, Jianglin Road 9, Sanya 572000, People's Republic of China

Email zhaoyl30I@I63.com
This article was published in the following Dove Press journal: Clinical Interventions in Aging

\begin{abstract}
Background: Functional dependence (FD) and vitamin D deficiency are common conditions in older adults. However, little is known about the relationship between FD and serum vitamin D status in centenarians. The current study was designed to evaluate the prevalence of FD and examine its relationship with serum vitamin D status among centenarians in China.
\end{abstract}

Subjects and methods: A cross-sectional study of a large sample of Chinese centenarians including 180 men and 822 women was conducted from June 2014 to December 2016. Home interviews, physical examinations, and blood analyses were performed in 958 centenarians following standard procedures. FD was evaluated using the Barthel index of activities of daily living (ADL). Serum 25-hydroxyvitamin D (25OHD) concentrations were measured as a marker of vitamin D status.

Results: The prevalence of centenarians with FD was $71.2 \%$. Vitamin D deficiency, lack of tea consumption, lack of outdoor activities, visual impairment, and fracture were predictors of FD. Centenarians in the lowest quartile of serum $25 \mathrm{OHD}$ concentration had an approximately threefold greater likelihood of FD than those in the highest quartile in multiple logistic regression models $(\mathrm{OR}=2.88 ; 95 \%$ CI 1.75-4.73; $P<0.001)$. The multivariable OR with a $1 \mathrm{ng} / \mathrm{mL}$ decrease in serum 25OHD concentration was 1.06 (95\% CI 1.04-1.08; $P<0.001$ ) for FD.

Conclusion: Serum 25OHD levels have important associations with FD in Chinese centenarians. Future research could focus on the value of intervening in the case of low serum 25OHD levels through vitamin D supplementation and improving ADL in the older population.

Keywords: centenarians, China, functional dependence, vitamin D

\section{Introduction}

Functional dependence (FD), an aspect of disability measured by impairment in the activities of daily living (ADL; eg, feeding, dressing, bathing, and toileting), ${ }^{1}$ is related to numerous adverse health outcomes such as cognitive decline, ${ }^{2}$ mental disorder, ${ }^{3}$ worse resident quality of life, ${ }^{4}$ and the increased caregiver stress,${ }^{5}$ and it plays a major role in transitions from independent living to nursing home care. ${ }^{1,6}$ In fact, with the rapid increase in life expectancy, the oldest old individuals (85 years of age and older) have been the fastest growing segment of the population. The oldest old individuals are more susceptible to FD with advanced age. ${ }^{7}$ The maintenance of physical function in late life is an important factor not only for a healthy and independent life in the community but also for preventing negative outcomes such as disability and early mortality. ${ }^{8-10}$ FD with aging is likely linked to several musculoskeletal and nutritional risk factors; thus, there is a further need to elucidate the impact of these factors in populations with advanced age. ${ }^{11,12}$ 
As a musculoskeletal risk factor, hypovitaminosis D is very common among older adults worldwide due to the reduced capacity of the skin to produce vitamin $\mathrm{D}$, reduced sunlight exposure caused by less outdoor activity, and impaired nutrition. ${ }^{13-15}$ Previous studies have investigated the relationship between FD and vitamin D deficiency in older adults. ${ }^{16-18}$ However, only a few studies with a limited sample size have examined its relationship among the oldest old individuals, and contentious findings have been reported. ${ }^{19,20}$ In addition, surveys on the relationship between FD and vitamin D levels in centenarians are scarce, especially in developing countries. Considering the high prevalence of vitamin D deficiency and functional decline as people age, the relationship between vitamin D status and functional performance warrants a more focused examination among the oldest old populations including centenarians.

For these reasons, the aim of the current study was to investigate the prevalence of FD and to evaluate its relationship with serum 25-hydroxyvitamin D (25OHD) status among a group of population-based centenarians in China.

\section{Subjects and methods Study population}

The sample of this study was obtained from the baseline survey of the China Hainan Centenarian Cohort Study (CHCCS), which was conducted in Hainan, China, from 2014 to 2016. Details of this study including sampling strategy and interview procedures have been described elsewhere. ${ }^{21,22}$ In brief, a total of 1,002 centenarians ( 180 men and 822 women aged 100 years and over) were interviewed, and blood samples were collected in this study. After excluding 44 participants who failed to provide complete information on physical examinations or blood analyses, 958 subjects (176 men and 782 women) were included in the final analysis.

Written informed consent was obtained from all men and women who participated in this study. The ethics committee of the Hainan branch of the Chinese People's Liberation Army General Hospital (Sanya, Hainan) approved the study protocol (no. of serial: 301hn11201601).

\section{Functional performance}

To evaluate the FD of the centenarians, the Barthel index on the ADL was used; ${ }^{23}$ the validity and reliability of this tool in Chinese older people have been well established. ${ }^{24}$ The Barthel index consists of ten items that measure a person's daily activities: grooming, feeding, dressing, bathing, toilet use, transferring from bed to chair, walking, stair climbing, bowel continence, and urinary continence. Each item of the ADL is rated on a scale with a given number of points assigned to each level of activity, and the total score ranges from 0 to 100 points with 5-point increments (Table S1). A higher score indicates higher levels of function. Items of the Barthel index are regarded as dependent if they are performed with any help from other people. ${ }^{25}$ Participants were deemed to have good functional capacity (independence) when the total score was $\geq 95$ points; participants with a total score of $<95$ points were regarded as dependent. ${ }^{26}$

\section{Vitamin D status}

Serum circulating 25OHD is commonly measured to reflect vitamin D status. ${ }^{27}$ Blood samples were obtained from each participant by an experienced nurse and transported in cold storage to the Clinical Laboratory of the Hainan branch of the Chinese PLA General Hospital. Serum 25OHD concentrations were measured by automated radioimmunoassay analyzers (DiaSorin, Stillwater, MN, USA) using a standard procedure. The inter-assay and intra-assay coefficients of variation for serum 25OHD in the current study were $8.3 \%$ and $6.7 \%$, respectively. Vitamin D deficiency was defined as $25 \mathrm{OHD}<20 \mathrm{ng} / \mathrm{mL}$ or $50 \mathrm{nmol} / \mathrm{L}$ according to the Endocrine Society Clinical Practice Guidelines. ${ }^{28}$

\section{Covariates}

Home interviews were conducted to collect data on the demographic details (age, gender, education, marital status, ethnicity, and living arrangements), season of blood collection, lifestyles (smoking, alcohol use, tea consumption, and outdoor activities), and common conditions (hypertension, diabetes, dyslipidemia, visual and auditory impairments, and fractures) of the participants. The ethnic origin was categorized as "Han" (the predominant ethnicity in China) and "non-Han"; the season of blood sampling was dichotomized into summer (April-September) and winter (October-March). The body mass index (BMI) was calculated as the weight in kilograms divided by the square height in meters. Blood samples from each participant were collected, and the plasma parathyroid hormone (PTH) levels were measured using automated electrochemiluminescence immunoassay (ECLIA) analyzers (Hoffman-La Roche Ltd., Basel, Switzerland). Smoking and alcohol use were categorized as "current," "past," and "never." The habits of daily tea consumption and outdoor activities (more than 10 minutes) were divided into "yes" or "no." Common conditions, including hypertension, diabetes, dyslipidemia, visual impairment, auditory impairment, and fractures, were recorded as self-reported combined with the medical records of the participants. 


\section{Statistical analyses}

Categorical variables were reported as numbers with percentages, while continuous variables were reported as the mean with SD, and they were compared by Student's $t$-test and chi-squared test, respectively. Multiple logistic regression analyses were performed to investigate the independent factors related to FD.

To examine its relationship with functional dependency, serum 25OHD concentrations were further categorized into quartiles (lowest, $<16.3 \mathrm{ng} / \mathrm{mL}$; second, $16.4-21.5 \mathrm{ng} / \mathrm{mL}$; third, 21.6-28.0 ng $/ \mathrm{mL}$; and highest, $>28.1 \mathrm{ng} / \mathrm{mL}$ ). Differences of the Barthel index score and the sum of dependent items of ADL among four groups according to the quartiles of serum 25OHD levels were evaluated using one-way ANOVA and linear polynomial contrast analyses.

To elucidate the level of serum 25OHD associated with $\mathrm{FD}$, logistic regression analyses were used to evaluate the odds of FD according to the quartiles of the serum 25OHD concentrations and a $1 \mathrm{ng} / \mathrm{mL}$ decrease in serum 25OHD concentrations with multiple adjustments for potential confounders. $P$ for trend was evaluated by entering FD in the model as a ranked variable. A $P$-value of $<0.05$ was considered statistically significant. All analyses were carried out using SPSS software (version 19.0 for windows, no. of serial: 5087722; IBM Corporation, Armonk, NY, USA).

\section{Results}

The study sample included 782 women (81.6\%) and 176 men (18.4\%) with the mean age of 102.8 years. The prevalence of FD and vitamin D deficiency in the total sample was $71.2 \%$ and $39.7 \%$, respectively. It was observed that $74.0 \%$ of women and $58.5 \%$ of men were functionally dependent $(P<0.001)$, and $80.0 \%$ of participants with vitamin D deficiency and $65.4 \%$ without vitamin D deficiency had FD $(P<0.001)$.

Table 1 summarizes the characteristics of participants with and without FD. The participants with FD had significantly lower values of serum 25OHD concentrations $(21.7 \pm 9.5$ vs $25.3 \pm 8.8 \mathrm{ng} / \mathrm{mL} ; P<0.001)$ than those without FD. Subjects who were female, were illiterate, lived with family members, were evaluated in winter, were vitamin D deficient, had a higher PTH concentration, participated in

Table I Characteristics of participants according to functional performance

\begin{tabular}{|c|c|c|c|c|}
\hline Characteristics & Overall $(\mathrm{N}=958)$ & Dependent $(n=682)$ & Independent $(n=276)$ & $P$-value \\
\hline Age (years), mean \pm SD & $102.8 \pm 2.7$ & $102.9 \pm 2.8$ & $102.6 \pm 2.7$ & 0.180 \\
\hline Gender, \% & & & & $<0.001$ \\
\hline Female & $782(81.6)$ & $579(84.9)$ & $203(73.6)$ & \\
\hline Male & $176(18.4)$ & $103(15.1)$ & $73(26.4)$ & \\
\hline Illiterate, \% & $872(91.0)$ & $629(92.2)$ & $243(88.0)$ & 0.046 \\
\hline Widowed, \% & $855(89.2)$ & $616(90.3)$ & $239(86.6)$ & 0.106 \\
\hline Han ethnicity, \% & $844(88.1)$ & $599(87.8)$ & $245(88.0)$ & 0.742 \\
\hline Live with, \% & & & & $<0.001$ \\
\hline Family members & 821 (85.7) & $604(88.6)$ & $217(78.6)$ & \\
\hline Alone & $129(13.5)$ & $7 I(10.4)$ & $58(21.0)$ & \\
\hline Institution & $8(0.8)$ & $7(1.0)$ & I $(0.4)$ & \\
\hline Winter, \% & 33I (34.6), vitamin D & $252(37.0)$ & $79(28.6)$ & 0.008 \\
\hline Current smoker, \% & $32(3.3)$ & $2 I(3.1)$ & II (4.0) & 0.631 \\
\hline Current alcohol user, \% & $85(8.9)$ & $48(7.0)$ & $37(13.4)$ & 0.002 \\
\hline Tea consumption, \% & $95(9.9)$ & $53(7.8)$ & $42(I 5.2)$ & 0.001 \\
\hline Outdoor activities, \% & $570(59.5)$ & 331 (48.5) & $239(86.6)$ & $<0.001$ \\
\hline \multicolumn{5}{|l|}{ Chronic conditions, \% } \\
\hline Hypertension & $623(65.0)$ & $438(64.2)$ & $185(67.0)$ & 0.409 \\
\hline Diabetes mellitus & $92(9.6)$ & $67(9.8)$ & $25(9.1)$ & 0.715 \\
\hline Dyslipidemia & $181(18.9)$ & $131(19.2)$ & $50(18.1)$ & 0.696 \\
\hline Visual impairment & $264(29.0)$ & $222(34.3)$ & $42(16.0)$ & $<0.001$ \\
\hline Auditory impairment & $293(30.6)$ & 231 (33.9) & $62(22.5)$ & $<0.001$ \\
\hline Fracture & $83(8.7)$ & $76(11.1)$ & $7(2.5)$ & $<0.001$ \\
\hline $\mathrm{BMI}$, mean $\pm \mathrm{SD}$ & $18.0 \pm 3.4$ & $17.8 \pm 3.4$ & $19.0 \pm 3.2$ & $<0.001$ \\
\hline Serum $250 H D, n g / m L$, mean \pm SD & $22.8 \pm 9.4$ & $21.7 \pm 9.5$ & $25.3 \pm 8.8$ & $<0.001$ \\
\hline PTH, pg/mL, mean \pm SD & $48.8 \pm 28.0$ & $50.2 \pm 29.3$ & $45.4 \pm 24.2$ & 0.017 \\
\hline Vitamin D deficiency, \% & $380(39.7)$ & $304(44.6)$ & $76(27.5)$ & $<0.001$ \\
\hline
\end{tabular}

Notes: Data are presented as the mean $( \pm \mathrm{SD})$ and frequency $(\%)$. Differences between groups were assessed by Student's $t$-test and chi-squared test. Abbreviations: BMI, body mass index; 25OHD, 25-hydroxyvitamin D; PTH, parathyroid hormone. 
Table 2 Significant correlates of FD

\begin{tabular}{l|l|l}
\hline Characteristics & OR (95\% CI) & P-value \\
\hline Vitamin D deficiency, \% & $1.58(1.13-2.20)$ & 0.007 \\
Tea consumption, \% & $0.36(0.21-0.62)$ & 0.001 \\
Outdoor activities, \% & $0.16(0.11-0.24)$ & $<0.00 \mathrm{I}$ \\
Visual impairment & $2.46(1.57-3.84)$ & $<0.00 \mathrm{I}$ \\
Fracture & $3.89(\mathrm{I} .65-9.04)$ & 0.002 \\
\hline
\end{tabular}

Notes: All the significantly different variables were included in the multivariate logistic regression model. Only significant predictive variables of FD are presented. Abbreviation: FD, functional dependence.

less outdoor activities, had visual or auditory impairment, and suffered a fracture were more likely to be functionally dependent $(P<0.05)$. Alcohol use and tea consumption were more common in functionally independent participants $(P<0.05)$. Multiple logistic regression analyses revealed that vitamin D deficiency, tea consumption, outdoor activities, visual impairment, and fracture were significant factors related to $\mathrm{FD}$ in this population (Table 2). In addition,

\section{Barthel score by vitamin D status}
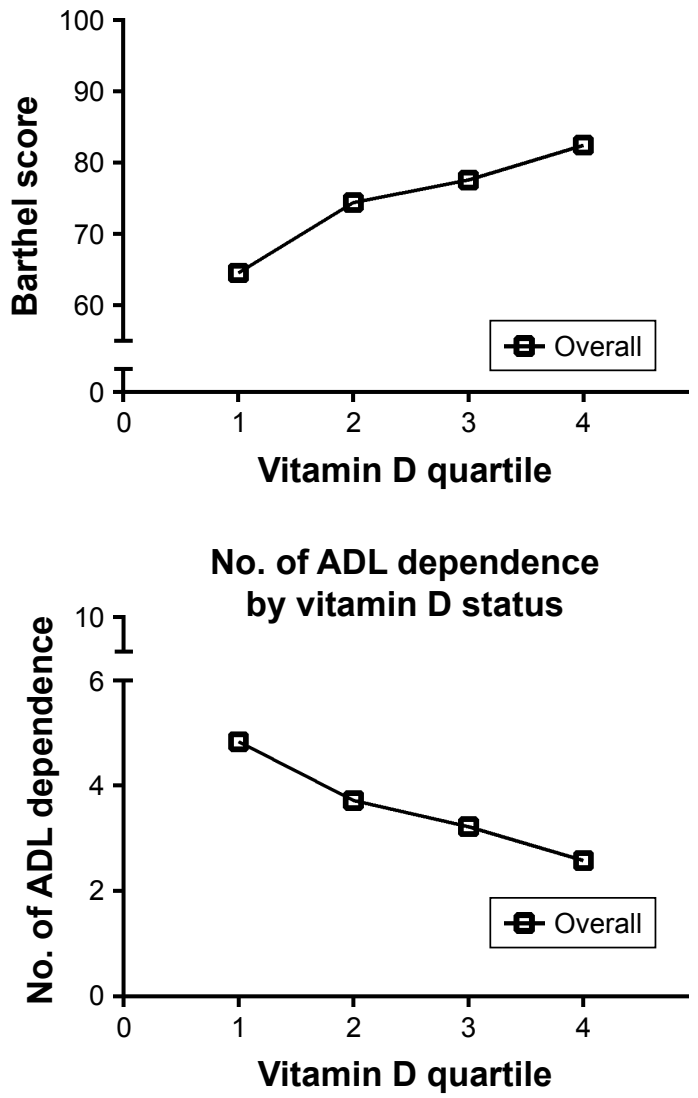

the participants with vitamin D deficiency have higher odds of dependence in eight functional items (including grooming, bathing, toilet use, dressing, feeding, stair climbing, transferring from bed to chair, and walking) than those without vitamin D deficiency (Table S2).

After participants were categorized into four groups according to the quartiles of serum $25 \mathrm{OHD}$ concentrations, an elevated trend of the Barthel index score (ranging from 64.6 in the lowest quartile to 82.5 in the highest quartile, $P$ for trend $<0.05$ ) and a decreased trend of the sum of dependent ADL items (ranging from 4.8 in the lowest quartile to 2.6 in the highest quartile, $P$ for trend $<0.05$ ) were observed. The trends remained constant after the stratification of participants by gender (Figure 1).

Table 3 summarizes that the adjusted OR for the lowest vs highest quartile of serum 250HD levels was 2.88 (1.75-4.73), and the adjusted odds of FD when comparing

Barthel score by vitamin D status
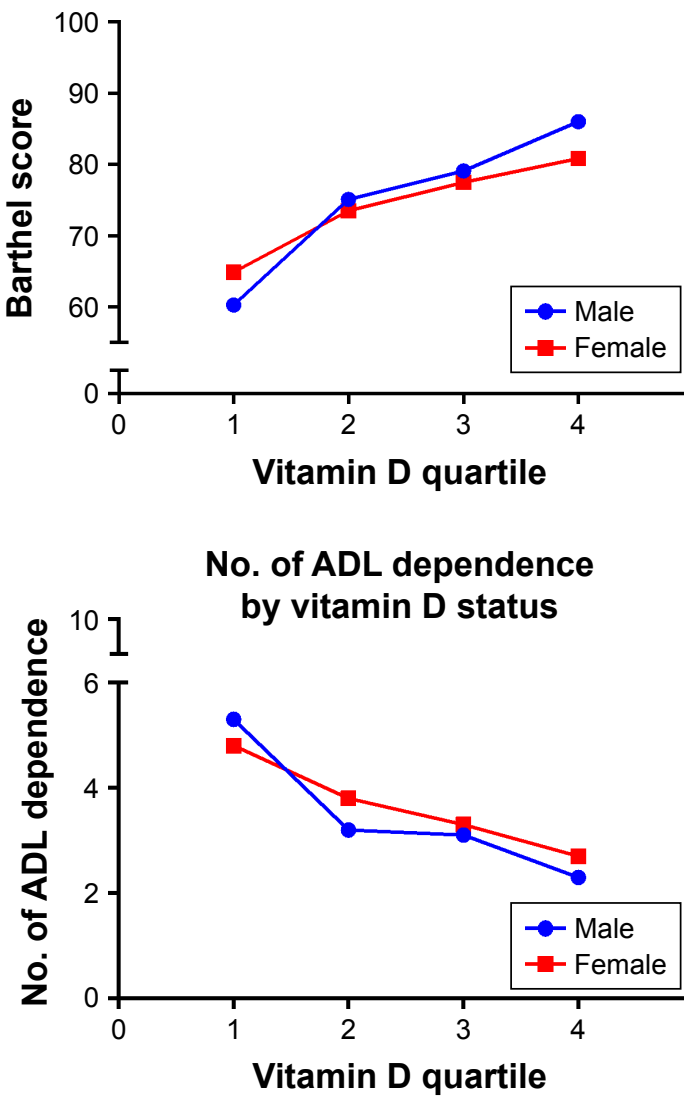

Figure I Functional performance by vitamin $D$ status and its gender difference.

Notes: Quartiles for serum $25 \mathrm{OHD}$ are as follows: quartile I, $<16.3 \mathrm{ng} / \mathrm{mL}$; quartile 2, 16.4 to $<21.5 \mathrm{ng} / \mathrm{mL}$; quartile $3,21.6$ to $<28.0 \mathrm{ng} / \mathrm{mL}$; quartile $4,28.1 \mathrm{ng} / \mathrm{mL}$ or higher. In general, elevated trends of the Barthel score (ranging from 64.6 in the first quartile to 82.5 in the fourth quartile) and descending trends of the sum of dependent items of ADL (ranging from 4.8 in the first quartile to 2.6 in the fourth quartile) were observed when serum $25 \mathrm{OHD}$ levels were elevated ( $P$ for linear trend $<0.00 \mathrm{I}$ ). After the participants were stratified by gender, the Barthel score increased from 64.9 in the first quartile to 80.9 in the fourth quartile among women and from 60.3 in the first quartile to 86.0 in the fourth quartile among men ( $P$ for linear trend $<0.00 \mathrm{I}$ ), and the sum of dependent items of $A D L$ among women and men decreased from 4.8 to 2.7 and from 5.3 to 2.3 , respectively ( $P$ for linear trend $<0.00 \mathrm{I}$ ).

Abbreviations: ADL, activities of daily living; 25OHD, 25-hydroxyvitamin D. 
Table 3 OR for FD according to the quartiles of serum 25OHD concentration

\begin{tabular}{|c|c|c|c|c|c|c|}
\hline & \multicolumn{4}{|c|}{$\begin{array}{l}\text { Serum } 250 \mathrm{OHD} \text { concentrations by quartile (no. of subjects with dependence/ } \\
\text { no of total subjects) }\end{array}$} & \multirow[t]{2}{*}{$\begin{array}{l}P \text { for } \\
\text { trend }\end{array}$} & \multirow[t]{2}{*}{$\begin{array}{l}\text { I } \mathrm{ng} / \mathrm{mL} \text { decrement of } \\
\text { serum } 250 \mathrm{OD}\end{array}$} \\
\hline & $\begin{array}{l}\leq 16.3 \mathrm{ng} / \mathrm{mL} \\
(199 / 237)\end{array}$ & $\begin{array}{l}|6.4-2| .5 \mathrm{ng} / \mathrm{mL} \\
(174 / 234)\end{array}$ & $\begin{array}{l}21.6-28.0 \mathrm{ng} / \mathrm{mL} \\
(165 / 243)\end{array}$ & $\begin{array}{l}\geq 28.1 \mathrm{ng} / \mathrm{mL} \\
(144 / 244)\end{array}$ & & \\
\hline Model I & $3.64(2.36-5.59)^{*}$ & $2.01(1.36-2.97)^{*}$ & $1.47(1.02-2.13)^{* *}$ & Reference & $<0.001$ & $1.06(1.04-1.08)^{*}$ \\
\hline Model 2 & $3.20(2.04-5.04)^{*}$ & $1.83(1.22-2.75)^{* * *}$ & $1.33(0.91-1.96)$ & Reference & $<0.001$ & $1.06(1.04-1.08)^{*}$ \\
\hline Model 3 & $2.88(1.75-4.73)^{*}$ & $1.91(1.23-2.96)^{* *}$ & $1.36(0.90-2.07)$ & Reference & $<0.001$ & $1.06(1.04-1.08)^{*}$ \\
\hline
\end{tabular}

Notes: Serum 25OHD levels were categorized into quartiles. Model I: unadjusted; Model 2: adjusted for age, gender, education, marital status, ethnicity, and living conditions; Model 3: further adjusted for season of sample collecting, BMI, plasma PTH levels, smoking, alcohol use, tea drinking, outdoor activities, and chronic conditions (hypertension, diabetes, dyslipidemia, visual and auditory impairments, and fractures). ${ }^{*} P<0.00 \mathrm{I} ; * * P<0.05$

Abbreviations: BMI, body mass index; FD, functional dependence; 25OHD, 25-hydroxyvitamin D; PTH, parathyroid hormone.

the second and third quartiles with the highest quartile were $1.91(1.23-2.96)$ and $1.36(0.90-2.07)$, respectively $(P$ for trend $<0.001)$. In addition, the multivariable adjusted OR with a $1 \mathrm{ng} / \mathrm{mL}$ decrease in serum $25 \mathrm{OHD}$ levels was 1.06 $(1.04-1.08, P<0.001)$.

\section{Discussion}

In this study, we observed an association between serum 25OHD levels and FD in a population-based sample of Chinese centenarians in Hainan province. Low serum 25OHD levels were associated with an increased prevalence of FD, and this association remained unchanged after adjusting for demographics and other potential confounders. Based on this Chinese study with a relatively large sample size, we added to the evidence of the association between vitamin D status and FD among extremely longevous people.

Several studies have shown an association between low serum vitamin D levels and FD among older individuals in developed countries such as USA and Japan. ${ }^{16,18}$ To the best of our knowledge, this is the first study to specifically focus on the relationship between FD and serum 25OHD levels in a representative sample of centenarians from a developing country.

The maintenance of physical function in old age is an important factor not only for a healthy and independent life in the community but also for preventing disability and early mortality. ${ }^{9,29}$ The current population-based study reported that nearly $3 / 4$ of centenarians were functionally dependent; in other words, these subjects exhibited a decline in physical function and required help in the basic ADL. The finding is consistent with that of previous studies that have reported that the prevalence of FD among centenarians was $81 \%$ in Japan, ${ }^{30} 76 \%$ in the USA, ${ }^{31} 67 \%$ in Poland, ${ }^{9}$ and $61 \%$ in Australia. ${ }^{32}$ However, a lower dependence rate of $53 \%$ was observed in Denmark. ${ }^{33}$ Despite the controversy surrounding this concept, it was observed that centenarians who were functionally dependent were more likely to have 1-year mortality at a rate of $11.1 \%$ compared to those who were not; ${ }^{9}$ further effective interventions should be addressed among this population with FD.

The current study found that lower vitamin D levels were associated with higher adjusted odds of FD in the very old. In addition, higher Barthel scores and fewer dependent items of ADL were observed as the serum 25OHD levels increased, suggesting that vitamin D may exert a dose-dependent effect on physical function. This result was comparable with the findings of other studies in old adult populations. ${ }^{16}$ However, a study of Georgia centenarians has reported that vitamin D status is not associated with physical function but rather with grip strength; this diverse result could be explained by different measurements used by the Georgia Centenarian Study Composite Scale which had very different components from the Barthel index. ${ }^{19}$

Several pathophysiological mechanisms may explain the link between low serum 25OHD levels and FD. First, vitamin D plays a beneficial role in the musculoskeletal system, and low serum 25OHD levels have been reported to be associated with osteoporosis, sarcopenia, and fractures, which lead to frailty and functional decline. ${ }^{34}$ The bioactive form of vitamin D, calcitriol, has been reported to regulate the cell biology of skeletal muscle, and the expression of vitamin D receptor (VDR) played a role in skeletal muscle regeneration following injury. ${ }^{35}$ VDR gene polymorphisms are also associated with variations in muscle strength in human beings, and genetic ablation of VDR leads to muscle fiber atrophy and motor deficits in mice. Second, vitamin D deficiency is associated with arterial stiffness and endothelial function, which have potential adverse influence on physical function. ${ }^{36-38}$ Calcitriol also modulates expression in vascular smooth muscle cells, thus protecting against vascular calcification and arterial stiffness and further reducing the risk of heart attack, stroke, or other cardiovascularrelated disabilities. ${ }^{39}$ Third, the immunomodulatory effect is also a physiological role of vitamin $\mathrm{D}$, where calcitriol 
regulates both adaptive and innate immunity and is related to host resistance to infection. ${ }^{40,41}$ Moreover, vitamin D has been reported to play a critical role in cognitive function and mental health. ${ }^{3,42}$ Vitamin D plays a neuroprotective role through several physiological mechanisms such as calcium homeostasis, neurogenesis, antioxidant defense, immunomodulation, and amyloid beta clearance. ${ }^{43-45}$

Serum 25OHD concentrations, not calcitriol, were measured as a marker of vitamin D status in this study. Quantitation of serum 25OHD provides a clinically useful and reliable assessment of one's vitamin D status for several reasons. ${ }^{46}$ First, the serum half-life of serum 25OHD is approximately 3 weeks. ${ }^{47}$ This rather long circulating half-life serves as an accurate marker of vitamin D scores obtained from both ultraviolet $B$ radiation and dietary intake over long periods. Second, liver production of serum 25OHD is not significantly regulated and is primarily dependent on substrate concentration. For these reasons, the measurement of serum 25OHD provides the best estimate of an individual's vitamin D status. ${ }^{27}$

Several observational studies have reported associations between functional declines with lower serum 250HD levels. ${ }^{16,48}$ In addition, a few randomized control trials have shown evidence that vitamin D supplementation improves functional performance. ${ }^{17,49}$ Thus, maintaining adequate vitamin $\mathrm{D}$ levels or the intake of vitamin D supplements among the very old may potentially help to prevent declines in physical function and preserve good ADL. ${ }^{18,19}$ Considering the low cost of vitamin D supplements and the lack of habitual intake of vitamin D supplementation among the elderly population in China, it is critical to closely examine the association between vitamin $\mathrm{D}$ levels and the preservation or improvement in physical function in this population.

\section{Limitations}

As there is little knowledge on FD and limited data on the relationship between functional decline and vitamin D status among the very old in developing countries, our data provide novel insights into the nature of this relationship among a representative sample of centenarians in China. Nevertheless, the study has some potential limitations. First, our results do not indicate any causal inferences due to the cross-sectional design, and additional cohort studies with follow-up data are essential to strengthen the evidence. Second, other factors such as cognitive impairment and psychological situations were not included in this study, and hence, potential confounders may remain unrecognized. Third, the data on chronic conditions were based on self-reported data; thus, the subjectivity derived from it should also be acknowledged in this study.

\section{Conclusion}

This study reports that FD is common in a population-based sample of centenarians in China, and serum 25OHD levels were independently and inversely associated with FD in this extremely longevous population. Future research could focus on the value of intervening in the case of low serum 25OHD levels through vitamin D supplementation and improving ADL in older populations.

\section{Acknowledgments}

We appreciate all the staff of the Hainan Centenarian Study for their continued cooperation and contribution to the field work. This study was supported by grants from the National Natural Science Foundation of China (81371561, 81773502) and the Key Research and Development Program of Hainan (ZDYF2016169, ZDYF2017095, and ZDYF2017126). The sponsors had played no role in the design, conduct, interpretation, review, approval, or control of this article.

\section{Disclosure}

The authors report no conflicts of interest in this work.

\section{References}

1. Portegijs E, Rantakokko M, Viljanen A, Sipilä S, Rantanen T. Identification of Older People at Risk of ADL Disability Using the Life-Space Assessment: A Longitudinal Cohort Study. J Am Med Dir Assoc. 2016;17(5):410-414.

2. Black SA, Rush RD. Cognitive and functional decline in adults aged 75 and older. J Am Geriatr Soc. 2002;50(12):1978-1986.

3. Yao Y, Fu S, Zhang H, et al. The prevalence of depressive symptoms in Chinese longevous persons and its correlation with vitamin D status. BMC Geriatr. 2018;18(1):198.

4. Lyu W, Wolinsky FD. The Onset of ADL Difficulties and Changes in Health-Related Quality of Life. Health Qual Life Outcomes. 2017; 15(1):217

5. Bruce DG, Paley GA, Nichols P, Roberts D, Underwood PJ, Schaper F. Physical disability contributes to caregiver stress in dementia caregivers. J Gerontol A Biol Sci Med Sci. 2005;60(3):345-349.

6. Samus QM, Mayer L, Onyike CU, et al. Correlates of functional dependence among recently admitted assisted living residents with and without dementia. J Am Med Dir Assoc. 2009;10(5):323-329.

7. Lunney JR, Lynn J, Foley DJ, Lipson S, Guralnik JM. Patterns of functional decline at the end of life. JAMA. 2003;289(18):2387-2392.

8. Visnjevac O, Lee J, Pourafkari L, Dosluoglu HH, Nader ND, Kritchevsky S. Functional capacity as a significant independent predictor of postoperative mortality for octogenarian ASA-III patients. J Gerontol A Biol Sci Med Sci. 2014;69(10):1229-1235.

9. Mossakowska M, Broczek K, Wieczorowska-Tobis K, et al. Cognitive performance and functional status are the major factors predicting survival of centenarians in Poland. J Gerontol A Biol Sci Med Sci. 2014; 69(10):1269-1275

10. Vermeulen J, Neyens JC, van Rossum E, Spreeuwenberg MD, de Witte LP. Predicting ADL disability in community-dwelling elderly people using physical frailty indicators: a systematic review. BMC Geriatr. 2011; 11:33. 
11. Daly RM, Rosengren BE, Alwis G, Ahlborg HG, Sernbo I, Karlsson MK. Gender specific age-related changes in bone density, muscle strength and functional performance in the elderly: a-10 year prospective population-based study. BMC Geriatr. 2013;13:71.

12. Singh DK, ManafZA, Yusoff NA, Muhammad NA, Phan MF, Shahar S. Correlation between nutritional status and comprehensive physical performance measures among older adults with undernourishment in residential institutions. Clin Interv Aging. 2014;9:1415-1423.

13. Hilger J, Friedel A, Herr R, et al. A systematic review of vitamin D status in populations worldwide. Br J Nutr. 2014;111(1):23-45.

14. Holick MF, Chen TC. Vitamin D deficiency: a worldwide problem with health consequences. Am J Clin Nutr. 2008;87(4):1080S-1086S.

15. Cabral MA, Borges CN, Maia JM, Aires CA, Bandeira F. Prevalence of vitamin D deficiency during the summer and its relationship with sun exposure and skin phototype in elderly men living in the tropics. Clin Interv Aging. 2013;8:1347-1351.

16. Sohl E, van Schoor NM, de Jongh RT, Visser M, Deeg DJ, Lips P. Vitamin D status is associated with functional limitations and functional decline in older individuals. J Clin Endocrinol Metab. 2013; 98(9):E1483-E1490.

17. Zhu K, Austin N, Devine A, Bruce D, Prince RL. A randomized controlled trial of the effects of vitamin D on muscle strength and mobility in older women with vitamin D insufficiency. $J$ Am Geriatr Soc. 2010; 58(11):2063-2068

18. Kojima G, Tamai A, Masaki K, et al. Prevalence of vitamin D deficiency and association with functional status in newly admitted male veteran nursing home residents. J Am Geriatr Soc. 2013;61(11):1953-1957.

19. Haslam A, Johnson MA, Hausman DB, et al. Vitamin D status is associated with grip strength in centenarians. J Nutr Gerontol Geriatr. 2014; 33(1):35-46.

20. Matheï C, van Pottelbergh G, Vaes B, Adriaensen W, Gruson D, Degryse JM. No relation between vitamin $\mathrm{D}$ status and physical performance in the oldest old: results from the Belfrail study. Age Ageing 2013;42(2):186-190.

21. He Y, Zhao Y, Yao Y, et al. Cohort Profile: The China Hainan Centenarian Cohort Study (CHCCS). Int J Epidemiol. 2018;47(3):694-695.

22. Yao Y, Chen X, Wu S, et al. Thyroid nodules in centenarians: prevalence and relationship to lifestyle characteristics and dietary habits. Clin Interv Aging. 2018;13:515-522.

23. Mahoney FI, Barthel DW. Functional evaluation: the Barthel index. Md State Med J. 1965;14:61-65.

24. Leung SO, Chan CC, Shah S. Development of a Chinese version of the Modified Barthel Index - validity and reliability. Clin Rehabil. 2007;21(10):912-922.

25. Quinn TJ, Langhorne P, Stott DJ. Barthel index for stroke trials: development, properties, and application. Stroke. 2011;42(4):1146-1151.

26. van Hartingsveld F, Lucas C, Kwakkel G, Lindeboom R. Improved interpretation of stroke trial results using empirical Barthel item weights. Stroke. 2006;37(1):162-166

27. Zerwekh JE. Blood biomarkers of vitamin D status. Am J Clin Nutr. 2008;87(4):1087S-1091S

28. Holick MF, Binkley NC, Bischoff-Ferrari HA, et al. Evaluation, treatment, and prevention of vitamin D deficiency: an Endocrine Society clinical practice guideline. J Clin Endocrinol Metab. 2011;96(7): 1911-1930.

29. Scott WK, Macera CA, Cornman CB, Sharpe PA. Functional health status as a predictor of mortality in men and women over 65. J Clin Epidemiol. 1997;50(3):291-296.

30. Ozaki A, Uchiyama M, Tagaya H, Ohida T, Ogihara R. The Japanese Centenarian Study: autonomy was associated with health practices as well as physical status. J Am Geriatr Soc. 2007;55(1):95-101.

31. Jopp DS, Park MK, Lehrfeld J, Paggi ME. Physical, cognitive, social and mental health in near-centenarians and centenarians living in New York City: findings from the Fordham Centenarian Study. BMC Geriatr. 2016;16(1):1
32. Richmond RL, Law J, Kay-Lambkin F. Physical, mental, and cognitive function in a convenience sample of centenarians in Australia. $J \mathrm{Am}$ Geriatr Soc. 2011;59(6):1080-1086.

33. Andersen-Ranberg K, Schroll M, Jeune B. Healthy centenarians do not exist, but autonomous centenarians do: a population-based study of morbidity among Danish centenarians. J Am Geriatr Soc. 2001;49(7): 900-908.

34. Hirani V, Cumming RG, Naganathan V, et al. Longitudinal Associations Between Vitamin D Metabolites and Sarcopenia in Older Australian men: The Concord Health and Aging in Men Project. J Gerontol A Biol Sci Med Sci. 2017;12;73(1):131-138

35. Srikuea R, Zhang X, Park-Sarge OK, Esser KA. VDR and CYP27B1 are expressed in $\mathrm{C} 2 \mathrm{C} 12$ cells and regenerating skeletal muscle: potential role in suppression of myoblast proliferation. Am J Physiol Cell Physiol. 2012;303(4):C396-C405.

36. Mozos I, Stoian D, Luca CT. Crosstalk between Vitamins A, B12, D, K, C, and E Status and Arterial Stiffness. Dis Markers. 2017;2017(2): 8784971.

37. Wang TJ, Pencina MJ, Booth SL, et al. Vitamin D deficiency and risk of cardiovascular disease. Circulation. 2008;117(4):503-511.

38. Caraba A, Crişan V, Romoşan I, Mozoş I, Murariu M. Vitamin D Status, Disease Activity, and Endothelial Dysfunction in Early Rheumatoid Arthritis Patients. Dis Markers. 2017;2017(8).

39. Mary A, Hénaut L, Boudot C, et al. Calcitriol prevents in vitro vascular smooth muscle cell mineralization by regulating calcium-sensing receptor expression. Endocrinology. 2015;156(6):1965-1974.

40. Cantorna MT, Zhu Y, Froicu M, Wittke A. Vitamin D status, 1,25dihydroxyvitamin D3, and the immune system. Am J Clin Nutr. 2004; 80(6 Suppl):S1717-S1720.

41. Christakos S, Dhawan P, Verstuyf A, Verlinden L, Carmeliet G. Vitamin D: Metabolism, Molecular Mechanism of Action, and Pleiotropic Effects. Physiol Rev. 2016;96(1):365-408.

42. Matchar DB, Chei CL, Yin ZX, et al. Vitamin D Levels and the Risk of Cognitive Decline in Chinese Elderly People: the Chinese Longitudinal Healthy Longevity Survey. J Gerontol A Biol Sci Med Sci. 2016;71(10): 1363-1368.

43. Dickens AP, Lang IA, Langa KM, Kos K, Llewellyn DJ. Vitamin D, cognitive dysfunction and dementia in older adults. CNS Drugs. 2011; 25(8):629-639.

44. Kalueff AV, Eremin KO, Tuohimaa P. Mechanisms of neuroprotective action of vitamin D(3). Biochemistry. 2004;69(7):738-741.

45. Kesby JP, Eyles DW, Burne TH, McGrath JJ. The effects of vitamin D on brain development and adult brain function. Mol Cell Endocrinol. 2011;347(1-2):121-127.

46. Holick MF. Vitamin D: importance in the prevention of cancers, type 1 diabetes, heart disease, and osteoporosis. Am J Clin Nutr. 2004;79(3): 362-371.

47. Clemens TL, Zhou XY, Myles M, Endres D, Lindsay R. Serum vitamin D2 and vitamin D3 metabolite concentrations and absorption of vitamin D2 in elderly subjects. J Clin Endocrinol Metab. 1986; 63(3):656-660.

48. Houston DK, Neiberg RH, Tooze JA, et al. Low 25-hydroxyvitamin D predicts the onset of mobility limitation and disability in communitydwelling older adults: the Health ABC Study. J Gerontol A Biol Sci Med Sci. 2013;68(2):181-187.

49. Janssen HC, Samson MM, Verhaar HJ. Muscle strength and mobility in vitamin D-insufficient female geriatric patients: a randomized controlled trial on vitamin D and calcium supplementation. Aging Clin Exp Res. 2010;22(1):78-84. 


\section{Supplementary materials}

Table SI Rating scale of ADL by Barthel index

\begin{tabular}{|c|c|c|c|}
\hline Task & Rating & Task & Rating \\
\hline Bathing & $\begin{array}{l}0=\text { dependent } \\
5=\text { independent }\end{array}$ & Grooming & $\begin{array}{l}0=\text { needs to help with personal care } \\
5=\text { independent }\end{array}$ \\
\hline Feeding & $\begin{array}{l}0=\text { unable } \\
5=\text { needs help for cutting and spread- } \\
\text { ing food or requires modified diet } \\
10=\text { independent }\end{array}$ & Dressing & $\begin{array}{l}0=\text { dependent } \\
5=\text { needs help but can do about half unaided } \\
10=\text { independent (including buttons, zips, } \\
\text { and laces) }\end{array}$ \\
\hline Bowel control & $\begin{array}{l}0=\text { incontinent or needs to be } \\
\text { given enemas } \\
5=\text { occasional accident } \\
10=\text { continent }\end{array}$ & Urinary control & $\begin{array}{l}0=\text { incontinent or catheterized and unable to } \\
\text { manage alone } \\
5=\text { occasional accident } \\
10=\text { continent }\end{array}$ \\
\hline Toilet use & $\begin{array}{l}0=\text { dependent } \\
5=\text { needs some help, but can } \\
\text { do something alone } \\
10=\text { independent (on and off, } \\
\text { dressing, wiping) }\end{array}$ & Stair climbing & $\begin{array}{l}0=\text { unable } \\
5=\text { needs help (verbal, physical, carrying aid) } \\
10=\text { independent }\end{array}$ \\
\hline Transferring from bed to chair & $\begin{array}{l}0=\text { unable, no sitting balance } \\
5=\text { major help (one or two people, } \\
\text { physical), can sit } \\
10=\text { minor help (verbal or physical) } \\
15=\text { independent }\end{array}$ & Walking (on level surface) & $\begin{array}{l}0=\text { immobile or }<20 \mathrm{~m} \\
5=\text { wheelchair independent, including } \\
\text { comers, }>20 \mathrm{~m} \\
10=\text { walks with the help of one person } \\
\text { (verbal or physical) }>20 \mathrm{~m} \\
15=\text { independent (but may use any aid such } \\
\text { as stick) }>20 \mathrm{~m}\end{array}$ \\
\hline
\end{tabular}

Abbreviation: ADL, activities of daily living.

Table S2 Functional status of participants according to serum 25OHD concentrations

\begin{tabular}{|c|c|c|c|c|c|c|}
\hline \multirow[t]{2}{*}{ Variables } & \multicolumn{2}{|c|}{ Serum 25OHD } & \multirow[t]{2}{*}{ OR $(95 \% \mathrm{Cl})$} & \multirow[t]{2}{*}{$\mathrm{OR}^{\mathrm{a}}(95 \% \mathrm{Cl})$} & \multirow[t]{2}{*}{$\mathrm{OR}^{\mathrm{a}}(95 \% \mathrm{Cl})$} & \multirow[t]{2}{*}{$P$-value } \\
\hline & $\begin{array}{l}<20 \mathrm{ng} / \mathrm{mL} \\
(398)\end{array}$ & $\begin{array}{l}\geq 20 \mathrm{ng} / \mathrm{mL} \\
(560)\end{array}$ & & & & \\
\hline \multicolumn{7}{|l|}{ Overall functional status } \\
\hline Dependence & $311(78.2)$ & $371(66.2)$ & $2.12(1.56-2.87)$ & $\rightarrow$ & $1.58(1.13-2.20)$ & 0.007 \\
\hline \multicolumn{7}{|l|}{ ADL items of dependence } \\
\hline Grooming dependence & $127(33.4)$ & $112(19.4)$ & $2.09(1.55-2.81)$ & $\rightarrow-$ & $1.58(1.14-2.20)$ & 0.006 \\
\hline Bathing dependence & $169(44.5)$ & $145(25.1)$ & $2.39(1.81-3.15)$ & $\rightarrow$ & $1.86(1.37-2.53)$ & $<0.001$ \\
\hline Toilet use dependence & $196(51.6)$ & $175(30.3)$ & $2.45(1.88-3.21)$ & $\rightarrow$ & $2.01(1.49-2.71)$ & $<0.001$ \\
\hline Fecal incontinence & $57(15.0)$ & $58(10.0)$ & $1.58(1.07-2.34)$ & -- & $1.50(0.94-2.26)$ & 0.091 \\
\hline Urinary incontinence & $61(16.1)$ & $65(11.2)$ & $1.51(1.04-2.20)$ & $=-$ & $1.32(0.86-2.01)$ & 0.201 \\
\hline Dressing dependence & $153(40.3)$ & $123(21.3)$ & $2.49(1.87-3.32)$ & $\rightarrow$ & $2.14(1.56-2.94)$ & $<0.001$ \\
\hline Feeding dependence & $131(34.5)$ & $122(21.1)$ & $1.97(1.47-2.63)$ & $\rightarrow$ & $1.69(1.22-2.34)$ & 0.002 \\
\hline Stair climbing dependence & $331(87.1)$ & 419 (72.5) & $2.56(1.80-3.64)$ & $\rightarrow$ & $2.08(1.43-3.02)$ & $<0.001$ \\
\hline Transferring dependence & $261(68.7)$ & $300(51.9)$ & $2.03(1.55-2.67)$ & $\rightarrow$ & $1.49(1.11-2.00)$ & 0.008 \\
\hline Walking dependence & $221(58.2)$ & $205(35.5)$ & $2.53(1.94-3.30)$ & $\rightarrow$ & $2.03(1.51-2.74)$ & $<0.001$ \\
\hline
\end{tabular}

Notes: Comparison of the overall and each item of FD between participants with and without vitamin D deficiency. Regarding the overall functional status, participants who were deficient in vitamin $D$ had a significantly higher FD rate than those without vitamin $D$ deficiency $(78.2 \%$ vs $66.2 \%$; $P<0.00$ I). The multivariable adjusted $O R$ for serum $25 \mathrm{OHD}<20 \mathrm{ng} / \mathrm{mL}$ vs $\geq 20 \mathrm{ng} / \mathrm{mL}$ was 1.58 (I.13-2.20) for FD. For ten items of the Barthel index, participants with lower serum $25 \mathrm{OHD}$ concentrations ( $<20 \mathrm{ng} / \mathrm{mL}$ ) exhibited a higher percentage of ADL dependence than those with higher serum $250 \mathrm{HD}$ concentrations ( $\geq 20 \mathrm{ng} / \mathrm{mL})$. ${ }^{\mathrm{a}} \mathrm{Adjusted}$ for age, gender, education, marital status, ethnic, living condition, season, BMI, plasma PTH levels, health-related lifestyles, and chronic conditions.

Abbreviations: ADL, activities of daily living; BMI, body mass index; FD, functional dependence; 25OHD, 25-hydroxyvitamin D; PTH, parathyroid hormone. 


\section{Publish your work in this journal}

Clinical Interventions in Aging is an international, peer-reviewed journal focusing on evidence-based reports on the value or lack thereof of treatments intended to prevent or delay the onset of maladaptive correlates of aging in human beings. This journal is indexed on PubMed Central, MedLine,
Dovepress

CAS, Scopus and the Elsevier Bibliographic databases. The manuscript management system is completely online and includes a very quick and fair peer-review system, which is all easy to use. Visit http://www.dovepress. $\mathrm{com} /$ testimonials.php to read real quotes from published authors. 